\title{
Work Related Factors and Office and Information Manager's Performance in Indigenous Organizations in Bayelsa State
}

\author{
Eke, Gift J., Ph.D, MABEN, MNIM, MTAMN1 $\quad$ Anele, Clement A., Ph.D MABEN, IORMS ${ }^{2}$ \\ 1.Department of Office and Information Management,Faculty of Management Sciences \\ Niger Delta University, Wilberforce Island Bayelsa State \\ 2.Department of Business Administration, Niger Delta University, Wilberforce Island Bayelsa State
}

\begin{abstract}
This study primarily focuses on the examination of the role of some work related factors and office and information manager's performance. The major factors investigated are: modern computers, information infrastructure, and office interconnectivity in Yenagoa Metropolis. The study employed the descriptive survey research design. Questionnaire was used as the primary instrument for data collection, after which such data was analyzed using simple percentage and the parametric statistics of Pearson Product Moment Correlation. Findings revealed that there is a strong relationship between modern infrastructure and employee task commitment, thereby enhancing performance. It is also found that there is an association between automation of information infrastructure and office and information manager's performance. Finally, it is also discovered that there is a relationship between interconnectivity of systems and office and information manager's performance. It is, therefore, concluded that work related factors are not necessarily financial incentives alone, which stimulate office and information managers' performance in indigenous work organizations. The study recommends that management should ensure proper training of office and information managers to acquire the necessary skills for optimal functioning.
\end{abstract}

Keywords: Job satisfaction, work commitment, incentive

DOI: $10.7176 / \mathrm{EJBM} / 11-20-04$

Publication date:July $31^{\text {st }} 2019$

\section{Introduction}

Quite a lot of shelf spaces have been devoted to how office managers optimal performance can be attracted at work (Aaron, 2000). Most of the behavioural thoughts which scholars have expressed are primarily aimed at employee motivation and necessary incentives. They have hitherto noted that organizational managers have often given a peripheral attention towards ensuring employee total commitment to work place goals. An environment conducive for pursuing work and individual goals is imperative and this is attained through owners/managerial efforts aimed at providing all necessary requirements for goals. This, of course, requires attaining to both psycho-educational and other extrinsic concern of employees. Indeed, literature has strong evidence for concern for organizational structures, rules and policies as commitment including imperatives, therefore, employees do not require other members to show commitment to work goals. This belief, which is essentially classical is yet to have offered the necessary incentive for organizational survival, rather, have set apart organizational and employee motives, thereby being unable to assess goals attainment. Employee commitment to tasks derives largely from the extent to which employers underscore the emotional, psychological and physical disposition of employees in their various work tasks. Inyanga and Akpama (2002) noted that though there appears a blurred complexity over job satisfaction, since there are varying individual work intent, satisfaction is easily accessed through the productive capacity of employees. In other words, though employees satisfaction may not be easily discerned, his productive level possibly will assure employers on how an employee is, with work tasks. Further, job satisfaction as an emotional phenomena cannot be seen, but it replaces how well employee perceives his work to be pleasurable, and assisting him in meeting his desired goals.

It is also common knowledge that employees enlist into the work place with the primary motive of satisfying basic needs and wants through earnings from his input to work. In this vein, Nwosu (2000) notes on coreinfluencing factors of employee commitment, which includes, work itself, supervising and promoting work groups, work conditions and remuneration. He practically harped on motivation, remuneration, believing that through such, the employee meets his needs and wants, which means satisfaction and resultant commitment.

Remuneration package is, no doubt a primary element in the employment contract. It refers to salary or wages and all allowances, and benefits payable to an employee in return for services rendered. Eze (2002) emphasized that pay has remained one of the singular variables that has remained as an incentive to buy labour, thereby contracting the hygiene factors of Herberg.

It is our belief that, while many other incentives might act to stimulate employees to higher performance, other incentives are central to secretarial employee commitment to work task and goal. Considering that, this study is aimed at analyzing critically the relationship between other work-related factors and secretarial employee performance. 


\subsection{The Problem}

Literature is replete with evidence of how high rate of ineffectiveness, low morale and non-employee commitment to work goals by secretarial, especially in the light of modern work facilities (Ohakwe, 2005; Robbins, 2005). The implication is that office and information managers, in their various work organizations, have not in real terms met the very essential self-goals that would probably enlist their commitments. On the other hand, while employers have tried to ensure customers satisfaction, as it enhances profitability for the firms, the satisfaction of the secretarial employees have not been given attention by the employers, who often at times do not meet their extrinsic expectations in terms of their work machines, given that new ones require new work skills.

Amah (2006) noted that operators of firms will often reconcile the employee performance with remuneration and instruments as a means of ensuring their commitments to organizational tasks and goals. It therefore means that, though some level of approval is given to incentives, these organizations have not examined the relationships between other work skills, related incentives and employee performance. It is against this backdrop that this study is focused on examining work related incentives and office and information managers in indigenous work organizations.

\subsection{Purpose of the Study}

The general objective of the study was to examine the relationship between work-related factors nd incentive and employee performance. Specifically, the objectives are:

1. To find out the degree to which the use of modern computers enhance the performance of office and information manager in indigenous work places;

2. To determine the extent to which automation of information infrastructures influence office and information manager performance;

3. To determine the degree to which office interconnectivity enhances office and information manager performance.

\subsection{Research Questions}

The following research questions were posed to address the general objectives of this study:

1. To what extent does the use of modern computer enhance the performance of office and information manager in indigenous organizations?

2. To what extent does automation of information infrastructure influence office and information manager performance?

3. To what extent does office interconnectivity enhance office and information manager performance?

\subsection{Research Hypotheses}

The following hypothesized statements were made to guide the study:

Ho1: There is no significant relationship between modern computers and office and information manager.

Ho2: There is no significant relationship between automation of infrastructure and office and information manager performance.

Ho3: There is significant relationship between office interconnectivity and office and information manager performance.

\subsection{Significance of the Study}

The role of the office and information manager in organizational activities cannot be over emphasized, hence their satisfaction at wok is imperative. To achieve this, various incentives and reward packages are drawn by organizational managers, all invented at attracting high performance and commitment of the employee. Most of the packages though robust, have seemingly failed to meet the purpose and intent with which they were drawn. It, therefore, means that modern work organizations have not done well in driving the actual incentives that will tend to bring about employee satisfaction. Further, the argument on the actual incentives had fixed majority towards monetary reward as the only basis for employee satisfaction since the employment relationship is built on wages and salaries.

In this regard, this study will be significant to the extent which it directs managers of organizations on other work incentives, relating to work machines as a means of satisfying office and information managers on their jobs.

Moreso, it will highlight some of the necessary instruments that are required to bring about employee job satisfaction. This study will also offer breakthrough for researchers who will be unreserved in enhancing employee performance at work.

\section{Review of Related Literature}

A. Nature and Concept of Job Satisfaction

The Concept of Job Satisfaction has attracted much scholastic attention, perhaps, that the performance level of the 
employee is a function of how much he is psychologically and attitudinally deposed to his task at work may have formed his mental focus.

Besides, the employee who undertakes work place task would not perform at optimum if expectations which might vary considerately are not in any way in sight.

Folayan (1986) believes that the effect is beyond life at work. He suggests that the work place goal and achievement of the individual employee no doubt serves to fulfil basic needs and wants.

Njoku (2007) exposed that a number of views have been offered regarding job satisfaction with performance. In other words, there had been desperate academic bids to establish the relationship between the two subjects. According to Luthans (1999), job satisfaction is in three dimensions. He went further in his stimulating contribution that first, job satisfaction is an emotional response to a job situation. This expresses belief in Ojo's (1993) assertion that job satisfaction is arbitrary and cannot be seen, but be inferred.

Secondly, job satisfaction is expressed in how well outcomes meet or exceed expectation. Put differently, production must be equal to or above marked capacity limits for the employees. Employees that feel equitable or adequately rewarded will perform at optimum, thereby improving productivity, which also expresses satisfaction in practical terms.

Conversely, workers who feel cheated or underplayed in terms of reward will perform below expectation, which equally means dissatisfaction. Thirdly, job satisfaction represents several job-related issues which includes the design of the job, scope of the job, and clarity of the job tasks.

The views of Locke (1976) quite substantiate the dimensions drawn by Luthans. He theorized that jobsatisfaction is a pleasurable or positive emotional state resulting from appraisal of one's job or job experience. Inferentially, the worker' expression in this regard must be that of someone whose expectations are met adequately or equitable. Although, there appears a common denominator, which is insistence on emotional expressions, the practical aspect as manifested in attainment of expectations must not be undermined. It, therefore, means that a satisfied worker would work so hard to meet targets.

The satisfaction expected is derivable from list of factors such as work environment that tasks itself, the wage expected, the job scope and design amidst others. Luthans (1999) though relied on preponderance of research evidence to shift from satisfaction and productivity, however, noted that satisfaction stem from reward level.

The main sticking issue from his argument that makes it academically misleading was the fact that, if reward stimulates satisfaction, satisfaction, it will invariably result to enhanced productivity, because a satisfied employee will show commitment that tends towards achieving desired results.

B. Financial (Monetary) Incentives

The subject of incentives for the employee has attracted much attention, both at work and in academics. While controversy has raged over what motivational incentives best suit the employee, thereby enlisting his deserved commitment to work place goals, the nature and type has evoked concern. Aaron (2000) theorized emphatically on financial incentives that results to satisfactory attitudes manifesting on the employee. His thesis was founded on the needs and wants satisfying syndrome that exists in man. In other words, man earns pay and wages in order to meet such basic needs. It also implies that an employee that is not provided with a desired pay level will not be satisfied in as much as his basic needs cannot be met.

C. Other Determinants of Work Commitment

Hullin (1969) suggested elaborately different determinants of job satisfaction. They made an incursion into work place variables that spurs satisfaction on the employee, not minding his level in the work place, hierarchy and environmental placement. Such factors, according to them include mentally challenging work, equitable rewards, supportive working conditions and supportive colleagues. We noted that equitable reward talks primarily into financial rewards that had been discussed, therefore, we shift attention to other work-related variables mentioned.

- Mentally Challenging Work

Employees tend to prefer jobs that give them opportunities to use their skills and abilities, and offer a variety of tasks, freedom and feedback on how well they are doing. These characteristics make work mentally challenging task and skills improvement enhances the quality of work life for the employees. Jobs that have too little challenge create boredom but too much challenge creates frustrations and feelings of failure. Under conditions of moderate challenge, most employees will experience pleasure and satisfaction.

- $\quad$ Supportive Working Conditions

Employees are concerned with their work environment for both personal comfort, and facilitating doing a good job. Studies demonstrate that employees prefer physical surroundings that are not dangerous and uncomfortable. Temperature, light, noise and other environmental factors should not be at either extreme. Most employees prefer working relatively modern facilities and with adequate tools and equipment.

- Supportive Colleagues

People get more out of work than merely or intangible achievements. For most employees, work also fills the need for social information. Not surprisingly, therefore, having friendly supportive co-workers leads to increased job satisfaction. Employee satisfaction is inbreeded when the immediate supervisor is understanding and friendly, 
offers praise to good performance, listens to employers' opinions, and show personal interest.

\section{Methodology}

\subsection{Design of the Study}

Considering the nature of the study, which involves all employees on the food processing sector in Yenagoa Metropolis of Bayelsa State, the survey method is deemed appropriate for the study.

\subsection{Population and Sampling Procedure}

The population of the study is infinite. All the office and information managers of the food processing organizations in Yenagoa Metropolis of Bayelsa State constitute the population of the study. Since the population is too large and cannot be feasibly covered, a sample size was obtained. In this instance, therefore, we judgmentally based our study on twenty (20) firms in Yenagoa, Bayelsa State. Furthermore, through a purposive sample exercise, the sample subject (office and information managers) were obtained from each of the firms.

\subsection{Research Instrument}

This study adopted questionnaire as its research instrument.

\subsection{Validity of the Instrument}

The instrument used for the generation of data was validated by two experts in the area of research and few employees who meaningfully responded to the questionnaire upon interest. This showed that the questions were valid.

\subsection{Data Analysis Techniques}

Our hypothesized statements were tested using the Pearson Product Moment Correlation statistical tool to establish the relationship between the variables studies.

The formula:

Where:

$$
r=\frac{n \sum x y-\left(\sum x\right)\left(\sum y\right)}{\sqrt{\left(n \sum x^{2}-\sum x\right)^{2}\left(n \sum y^{2}-\sum y\right)^{2}}}
$$

$\mathrm{r}=$ Correlation coefficient

$\mathrm{y}=$ Dependent variable

$\mathrm{x}=$ Independent variable

$\mathrm{n}=$ Number

To establish the significance of the result of the correlation analysis, the student's t-statistics was used.

$$
t=\sqrt{\frac{r-0}{\frac{1-r^{2}}{n-2}}}
$$

\section{Findings}

Table 1: Administration and retrieval of questionnaire

\begin{tabular}{|l|l|l|l|}
\hline $\begin{array}{l}\text { Number } \\
\text { of Data }\end{array}$ & $\begin{array}{l}\text { Number of Questionnaire } \\
\text { Administered each stratum }\end{array}$ & $\begin{array}{l}\text { Number of Questionnaire } \\
\text { Retrieved from each stratum }\end{array}$ & Percentage of Success \\
\hline I & 20 & 9 & 60 \\
\hline II & 20 & 13 & 87 \\
\hline III & 20 & 13 & 87 \\
\hline IV & 20 & 15 & 100 \\
\hline V & 20 & 8 & 53 \\
\hline VI & 20 & 13 & 87 \\
\hline
\end{tabular}

Source: Survey Data, 2019

\subsection{Test of Hypotheses}

As earlier stated hypotheses were tested using the Pearson Product Parametric Statistics. Tests were conducted at $95 \%$ confidence interval and 0.05 significance level.

Hypothesis One

$\mathrm{Ho}_{1}$ : There is no significant relationship between modern computers and office and information managers' performance 
Table 2

\begin{tabular}{|l|l|l|l|l|}
\hline Computers $(\mathrm{X})$ & Performance $(\mathrm{Y})$ & $\mathrm{X}^{2}$ & $\mathrm{Y}^{2}$ & $\mathrm{XY}$ \\
\hline 46 & 39 & 2116 & 1521 & 1794 \\
\hline 21 & 17 & 441 & 289 & 357 \\
\hline 13 & 17 & 169 & 289 & 221 \\
\hline 8 & 11 & 64 & 121 & 88 \\
\hline 5 & 9 & 25 & 81 & 45 \\
\hline 93 & 93 & 2815 & 2301 & 2505 \\
\hline
\end{tabular}

Source: Survey Data, 2019

$\mathrm{r}=0.843$

tcal $=4.24$

$\mathrm{ttab}=\mathrm{df}=3 ;=3.18$

Decision: The $\mathrm{r}=0.843$ shows a strong positive relationship between modern computers and office and information managers commitment. Again, since the tcal is greater than the ttab, we reject the null hypothesis, which means a significant relationship exists between modern computers and office and information managers' performance. Hypothesis Two

Ho2: There is no significant relationship between automation of information infrastructure and office and information manager performance.

Table 3

\begin{tabular}{|l|l|l|l|l|}
\hline Computers (X) & Performance (Y) & $\mathrm{X}^{2}$ & $\mathrm{Y}^{2}$ & $\mathrm{XY}$ \\
\hline 18 & 39 & 324 & 1521 & 720 \\
\hline 32 & 17 & 1024 & 289 & 544 \\
\hline 24 & 17 & 576 & 289 & 408 \\
\hline 9 & 11 & 81 & 121 & 99 \\
\hline 10 & 9 & 100 & 81 & 90 \\
\hline 93 & 93 & 2105 & 230 & 1843 \\
\hline
\end{tabular}

Source: Field Survey, 2019

$\mathrm{r}=0.629$

tcal $=2.98$

$\mathrm{ttab}=\mathrm{df}=3.18$

Decision: There is a strong relationship between automation and office and information manager commitment to task as shown by the figure 0.629 . The relationship is, however, not significant since the tcal is less than ttab. Therefore, the null hypothesis is accepted.

Hypothesis Three

Ho3: There is no significant relationship between office interconnectivity and office and information manager performance.

Table 4

\begin{tabular}{|l|l|l|l|l|}
\hline Computers (X) & Performance (Y) & $\mathrm{X}^{2}$ & $\mathrm{Y}^{2}$ & $\mathrm{XY}$ \\
\hline 20 & 39 & 400 & 154 & 78 \\
\hline 37 & 17 & 1369 & 289 & 629 \\
\hline 20 & 17 & 400 & 289 & 340 \\
\hline 12 & 11 & 133 & 121 & 132 \\
\hline 4 & 9 & 165 & 81 & 36 \\
\hline 93 & 93 & 2329 & 2301 & 1917 \\
\hline
\end{tabular}

Source: Field Survey, 2019

$\mathrm{r}=0.319$

tcal $=0.58$

$\mathrm{ttab}=\mathrm{df}=3.18$

Decision: The $r$ value (0.319) shows a very weak relationship exists between interconnectivity and office and information manager commitment to task. This relationship has also shown insignificance as the tcal is less than ttab which implies that null hypothesis is accepted.

\subsection{Discussion of Findings}

The major objective of this study was to investigate the extent to which work related factors and skills influence office and information manager performance in indigenous work organization in the Yenagoa Metropolis of Bayelsa State. The major variables investigated in relation to office and information manager performance were modern computer, automation of information infrastructure, training on work skills and inter-connectivity. Inyang\&Akpama (2002) noted that the key to high performance and productivity is the ability of the organization 
to effectively harness the various motivational instruments to ginger the workers to perform at optimum level.

Ohakwe et al (2005) argued strongly that employees would be willing to take responsibilities of their interest in relation to their desire. Its needs are provided by employers through provision of rewards that would assist to accommodate and satisfy their needs. They noted that it is possible to create an atmosphere of employee commitment, even with less supervision.Aldag (1987) on motivation, attests to how employees require the satisfaction of some needs at every point in time as the means of motivating employees. We also know that motivation ensured commitment, as it is anything that influenced, energizes, competes, drives, induces or stimulates one to do things happily and satisfactorily without complaints. It becomes clear that the best motivational instruments that would perform the magic are those of financial content orientation. Importantly, the nature of the tasks in the sector required doggedness and tenacity to remain steadfast at work, the zeal to remain so committed is reinforced with the hope that the reward for such service is comparatively worth it.

The study has shown that employees in the food processing sector have high regard for financial rewards, and this has been shown as one of the major incentives used in the sector.

Commonly, employees are viewed as people with great financial weaponry to tackle their needs, hence, the need to be at work. There is always an implied expectation in terms of reward for employee input to the entire production process. Eze (2001) has carefully come to the conclusion that potential incentives are the best measurable instrument to reward workers in highly sensitive work environment as workers are immensely gladdened with such arrangement. It commits his emotion which manifests his ability to ensure work accomplishment.

Although, employees may stimulate to high level inputs, Eze (2001) suggests that the varying needs of employees require that there should be variation in the choice of incentives application. In other words, what could possibly motivate or stimulate employee may vary across sectors, individuals or social groups. There is always an implied expectation in terms of reward for employee input to the entire production process. The implication of this is that managers should continuously understand what form of incentives will maximize the objective of the organization. In this study, the sector studies and the unique context in relation to the city where our study was conducted has shown variation on the outcome of incentive forms and employee commitment to task. From the analysis, over-time and medical allowances should have a very strong and significant relationship with employee commitment tasks. The import of this outcome could be linked to the responses from the respondents interviewed that the nature of the job tasks in the sector requires much energy and time, so after the normal work hours, additional financial incentive is only what they need to meet target. Again, much of human energy is used up, and little time made available for rest. It often manifests in sickness and that is why medical incentive is considered important. In relation to this housing incentive, the relationship showed was very weak and insignificant. These phenomena tend to give credence to Maslow's belief that satisfied need will not stimulate employees interest, rather, they will seek for higher level needs.

Other incentives identified as that which would boost employees commitment include: salaries and wages, job security, promotion, job growth, conducive working environment, recognition and advancement, interpersonal relations, children education, lunch subsidy, life assurance schemes, and challenging work.

\section{Conclusion}

Work-related facilities and skills play important roles in determining the motivational direction of office and information manager in indigenous work organizations. In line with this thinking, this study has found that work related factors like modern computers, automation of information infrastructures, training and interconnectivity motivate office and information managers to high level. The phenomenal relationship exhibited attest to the role of such factors acting as incentives in ensuring that office and information managers are committed to their responsibilities, both for long-term gains for employees and overall effectiveness of the organization.

\subsection{Recommendations}

In light of the findings, the following recommendations were proffered:

1. Management of organizations should create enabling work environment by training office and information managers on needed skills to operate modern machines at work.

2. Office and information managers in modern work office should be made to appreciate the role of modern machines in providing quality service delivery to customers and clients alike.

3. Management of organizations should strive to appreciate the strategic importance of work-related factors that are likely to motivate office and information managers towards enhancing performance and not necessarily monetary incentives alone.

4. Managements should also use the financial incentives to attract highly qualified personnel, retain them, and improve their skills towards optimal performance. 


\section{References}

Aaron, B. D. (2000). Job characteristics and employee motivation: An empirical analysis. Journal of Management $11(2), 16-27$

Aldag, R. J. (1987). The intrinsic-extrinsic dichotomy: towards conceptual clarity. Academy of Management Review. 16(14), 102-107.

Amah, E. (2006). Human Resource Management. Port Harcourt: Amethyst and Colleagues Publishers.

Eze, F. (2002). Human Resource Management in Nigeria. Enugu: Mekanand Publications.

Hullin, D. T. (1968). A test of refinedment of equity sensitivity construction. Journal of Organizational behavior. Vol.14, 80-87.

Locke, E. A. (1968). Towards a theory of task performance and incentives. Organizational Behaviour and Human Performance. 3(21), 32-43.

Njoku, S. (2007). Organizational Behaviour. Beston: McGraw-Hill Books Co.

Nwosu, B. O. (2000). Office Management in Nigeria. Owerri: Chin and Chin Ventures Ltd.

Ohakwe, S. N. (2005). Office Administration. Owerri: Bon Publications.

Ojo, A. A. (1993). Managing the Human Resource in Africa: The Issues. Lagos: Lagos University Press

Robbins, S. (2003). Organizational Behaviour. New York: Pearson Education Inc. $10^{\text {th }}$ ed. 